\title{
MODELING AND OPTIMIZATION OF FLANK WEAR AND SURFACE ROUGHNESS OF MONEL-400 DURING HOT TURNING USING ARTIFICIAL INTELLIGENCE TECHNIQUES
}

\author{
M. Hanief*, M. S. Charoo \\ Mechanical Engineering Department, National Institute of Technology Srinagar, \\ $J \& K$, India
}

Received 29.01.2020

Accepted 13.04.2020

\begin{abstract}
This work aims to model and investigate the effect of cutting speed, feed rate, depth of cut and the workpiece temperature on surface roughness and flank wear (responses) of Monel-400 during turning operation. It also aims to optimize the machining parameters of the above operation. A power-law model is developed for this purpose and is corroborated by comparing the results with the artificial neural network (ANN) model. Based on the coefficient of determination $\left(\mathrm{R}^{2}\right)$, mean square error (MSE), and mean absolute percentage error (MAPE) the results of the power-law model are found to be in close agreement with that of ANN. Also, the proposed power law and ANN models for surface roughness and flank wear are in close agreement with the experiment results. For the power-law model $R^{2}, M S E$, and $M A P E$ were found to be $99.83 \%, 9.9 \times 10^{-4}$, and $3.32 \times 10^{-2}$, and that of ANN were found to be $99.91 \%, 5.4 \times 10^{-4}$, and $5.96 \times 10^{-2}$, respectively for surface roughness and flank wear. An error of $0.0642 \%$ (minimum) and $8.7346 \%$ (maximum) for surface roughness and $0.0261 \%$ (minimum) and $4.6073 \%$ (maximum) for flank wear were recorded between the observed and experimental results, respectively. In order to optimize the objective functions obtained from power-law models of the surface roughness and flank wear, GA (genetic algorithm) was used to determine the optimal values of the operating parameters and objective functions thereof. The optimal value of $2.1973 \mu \mathrm{m}$ and $0.256 \mathrm{~mm}$ were found for surface roughness and flank wear, respectively.
\end{abstract}

Keywords: model; artificial neural network; genetic algorithm; flank wear; surface roughness; turning.

*Corresponding author: M. Hanief, hanief@nitsri.net 


\section{Introduction}

Hard turning is a turning of material with a hardness range from 45 to 68 HRC (Fig. 1). Hard turning has many advantages in addition to the cost of operation, such as faster metal removal rate, reduced cycle time, good surface finish and environmentally friendly, over grinding operation [1]. In machining, the material is strain-hardened due to the presence of retained austenite. The new machining industries aim to produce components at low product cost with good quality in minimum time. To achieve a good cutting performance in turning, the selection of optimum cutting parameters is important. Machinability of hardened materials was evaluated by cutting force for better surface roughness and tool wear by several researchers.

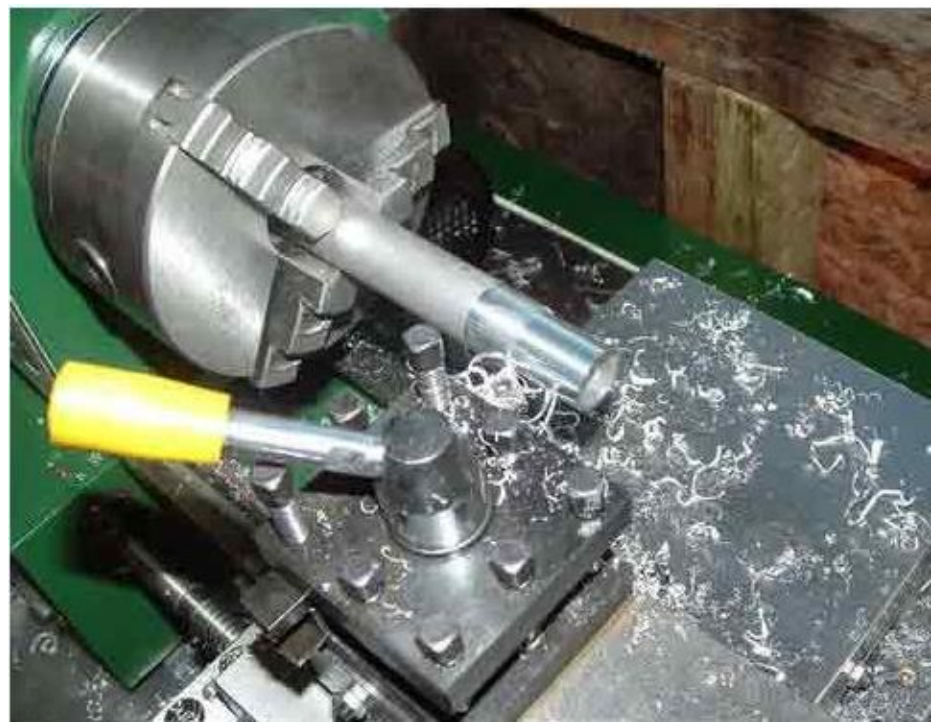

Fig. 1. Turning operation on the lathe.

However, turning the hard material to get a minimum surface roughness with minimum tool wear is difficult. Katuku et al. [2] conducted experimental work in dry cutting conditions on austempered ductile iron (ASTM Grade 2). The cutting forces, chip characteristics and tool wear were analyzed with PCBN cutting tools. The result revealed that the optimum cutting speed for better tool life and flank tool wear is 150 to $500 \mathrm{~m} / \mathrm{min}$. In another work, Marcelo Vasconcelos de Carvalho et al. [3] investigated the machinability of ADI (ASTM grades 2 and 3). It has been reported that minimum surface roughness and higher tool wear observed when turning ADI grade3 with a higher tool nose radius. In another work, Tuğrul Özel and Yiğit Karpat [4] developed the prediction model using regression and neural networks in hard turning for surface roughness and tool wear by CBN inserts. Minimum surface roughness was obtained at high workpiece hardness with high cutting speed. Higher tool wear was obtained with the higher cutting speed at lower feed rates. Lower feed rate gives a good surface finish. Zahia Hessainia et $a l$. conducted experimental work on hard turning. The surface roughness was predicted with the use of cutting parameters and tool vibrations. The mixed ceramic cutting tool $\mathrm{Al}_{2} \mathrm{O}_{3} / \mathrm{TiC}$ was used. They found that the feed rate was a more dominating factor than the 
tool vibration in affecting the surface roughness [5]. Mustafa Gunay and Emre Yuce applied the Taguchi method for cutting conditions optimizing for surface roughness in turning of white cast iron (high alloy). Mandal et al. [6] investigated the optimization of cutting parameters for tool flank wear using newly developed cutting tool Zirconia Toughened Alumina (ZTA). Taguchi method and regression analysis were used to optimize the cutting parameters. It has been observed that the tool wear was highly affected by the depth of cut.

Nickel-based alloys have found wide applications ranging from automobile to the aircraft sector owing to its properties such as excellent tensile strength, corrosion resistance, ability to withstand elevated temperatures [7]. Monel-400, a solid solution of $\mathrm{Ni}$ and $\mathrm{Cu}$, is one of the nickel-based alloys in this category. Machining of such materials by conventional methods encounters several problems which include rapid tool wear, excessive cutting forces, more pronounced surface roughness [8]. The nickel-based alloys have been machined by different machining operations-hard turning, electro-dischargemachining etc. These machining operations have limitations due to high cutting tool cost and low (metal removal rate) MRR. Hot machining offers a good opportunity to machine these alloys. Several investigations have been conducted by the researchers to study hot machining. Parida and Maity [9] investigated the machinability of several nickel-based alloys at elevated temperatures. The machinability in the hot condition was improved, comparing the machinability at room temperature. The tool life was investigated by Ozler et al. [10] during the hot machining of high manganese steel using flame heating. It was found that the cutting speed has more effect on tool life than the feed rate and depth of cut. Ginta et al. [11] found that the machinability performance of titanium alloys at elevated temperatures is better as compared to that at room temperature. Similar results have been reported by other researchers regarding the induction heat machining, laserassisted machining and plasma-assisted machining [12]. Optimization of machining parameters is necessary as it directly influences the cost, time and reliability of machining operations. Ranganathan and Senthilvelan [13] used a multi-objective optimization method in hot machining of AISI 316 using the grey Taguchi method. They took surface roughness, material removal rate and tool life as system responses. Optimization of machining parameters using flame heating has been studied by researchers in turning of Monel-400 [14], Inconel 625 [13] and Ni-hard material [16] for improving machinability. They used grey Taguchi, desirability, data envelopment analysis for optimization of machining parameters. Zhang et al. [17] implemented a combined method of RSM and a non-sorting genetic algorithm to optimize the wire-electro-discharge machining parameters. Aouici et al. [18] applied surface response methodology to optimize the effect of the cutting parameters on surface roughness, cutting force, specific cutting force, and power consumption in hard turning of AISI D3 steel. Feed rate is the most influential parameter affecting the cutting force and surface roughness compared to other parameters. Gupta et al. [19] studied the mathematical modeling of surface roughness, tool wear and power consumption in turning operation using surface response methodology combined with artificial neural network and support vector regression. Aouici et al. [20] applied RSM to investigate cutting force and surface roughness by taking different hardness of AISI H11 steel. Koyee et al. [21] optimized the machining parameters on flank wear, chip volume ratio, cutting force and cutting power using response surface methodology combined with cuckoo search algorithm in turning duplex steel. Parida [22] discussed the chip geometry in the hot machining of Inconel 718. He 
concluded that chip geometry such as the degree of segmentation, serration frequency, and equivalent chip thickness decreased with the increase of heating temperature. Venkatesh and Chandrakar [23] analyzed the heat-assisted turning of a nickel-base alloy. They concluded that heating on the surface of the workpiece reduces cutting force, surface roughness and tool wear compared to room temperature machining. Nickel-based alloys have been studied through experimental investigations and modeling by several researchers but only one article could be found in the published literature on modeling of hot machining of Monel-400 using response surface methodology. In order to have a much better and more accurate model, power law and ANN have been used for modeling the hot machining of Monel 400. The optimization of the machining operation has been carried out through GA, where the power-law model has been used as an objective function. Palani et al. [24] developed a mathematical model for Ra, tool wear ratio and MRR in-terms of machining parameters and the model developed was used as desirability function for carrying out the optimization of the machining parameters. Durairaj and Gowri [25] investigated the Ra and tool wear during the machining of Inconel-600 using a genetic algorithm for parametric optimization to improve tool life and surface finish. A multi-pass turning parameter optimization was performed by Rao and Kalyankar [26] using a teaching-learning based optimization algorithm. The results were compared with GA and Particle swarm optimization techniques. Asiltürk et al. [27] performed the optimization of parameters using Taguchi's method that influence Ra in Co28Cr6Mo material. It was concluded that tooltip radius is the dominant factor that affects surface quality. Selvakumar and Ravikumar [28] conducted optimization for minimum tool wear and surface roughness during machining of Titanium alloy.

\section{Procedure and Modelling}

Power-law model

The relationship between the output, i.e. surface roughness and flank wear, and the machining parameters can be expressed as

$$
R_{i}=C_{i} . V^{v_{i}} \cdot F^{f_{i}} \cdot D^{d_{i}} \cdot T^{t_{i}}
$$

$i=1,2$ where subscript 1 and 2 corresponds to surface roughness and flank wear.

i.e. $R_{1}$ and $R_{2}$ are surface roughness and flank wear, $V$, is cutting speed, $F$ is feed rate, $D$ is the depth of cut, and $T$ is temperature. Unknown constants are $C_{i}, v_{i}, f_{i}, d_{i}$, and $t_{i}$-determined from the experimental data. In order to find these constants, Eq. (1) is linearized by logarithmic transformation. We get

$$
\ln R_{i}=\ln C_{i}+v_{i} \ln V+f_{i} \ln F+d_{i} \ln D+t_{i} \ln T
$$

Eq. (2) can be rewritten as a linear mathematical model as

$$
\bar{R}=\bar{C}_{\imath}+v_{i} \cdot \bar{V}+f_{i} \cdot \bar{F}+d_{i} \cdot \bar{D}+t_{i} \cdot \bar{T}
$$

where $\bar{C}=\ln C, \quad \bar{V}=\ln V, \quad \bar{F}=\ln F, \quad \bar{D}=\ln D$ and $\quad \bar{T}=\ln T$

using least square

$$
\beta_{i}=\left(X_{i}^{T} \cdot X_{i}\right)^{-1} \cdot X_{i}^{T} \cdot R_{i} \quad i=1,2
$$


we find the coefficients using Eq. (5) and the experimental data of Parida et al. [30]. Where

$$
\begin{aligned}
& \beta_{i}=\left[\begin{array}{c}
C_{i} \\
v_{i} \\
f_{i} \\
d_{i} \\
t_{i}
\end{array}\right] \\
& X_{i}=[\text { array of input data }]
\end{aligned}
$$

\section{ANN model}

The capacity of ANN to solve nonlinear problems has attracted the attention of the researchers to solve the problems of machining. So, it has been used in this work too. ANN has many layers that depend on the complexity and type of problem. In general, it has an input layer, hidden layer and output layer. The input data are processed in the hidden layer. Next, the hidden layer computes the output and this is further processed in the output layer to produce the final results. The hidden layer and the output layer compute results based on the transfer functions. In this work, tansig and purelin functions were used as transfer functions in the hidden layer and output layer, respectively, and are given in Eqs. (8a) and (8b). The schematic representation of the ANN model is shown in Fig. 2.

$$
\begin{aligned}
& F(x)=\frac{e^{x}-e^{-x}}{e^{x}+e^{-x}} \\
& F(x)=x
\end{aligned}
$$

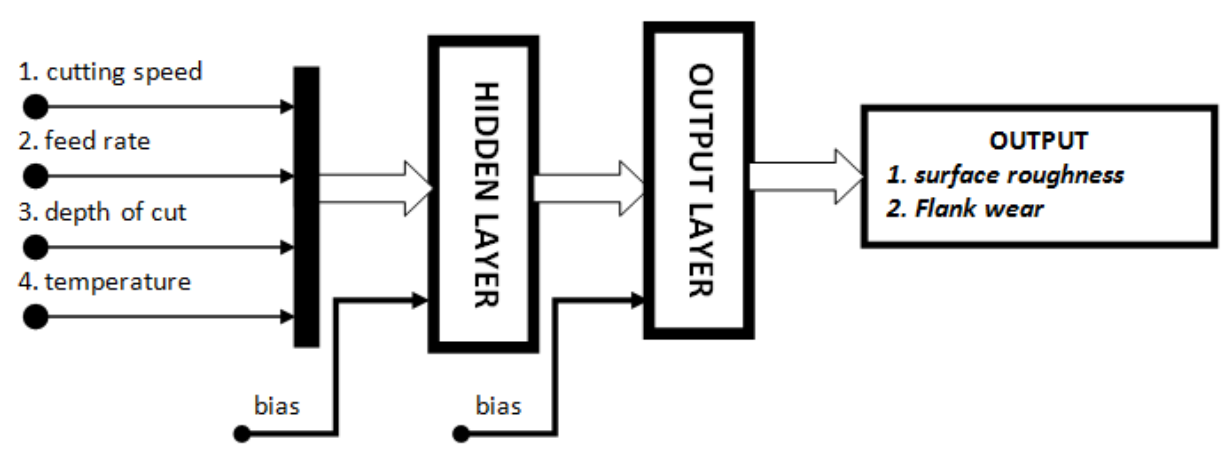

Fig. 2. Schematic of ANN structure used for modeling. 
The ANN is initiated by training, where the input, along with the output, is introduced to the network, and the weights are set randomly. To achieve a satisfactory level of performance, weights are altered by the backpropagation algorithm to minimize the mean square error (MSE). In the backpropagation algorithm technique, the weights are adjusted by propagating weight changes back to the input neuron from the output neuron [29]. The training process is stopped when a satisfactory level of performance is attained. The network generated thereof uses these weights to make the decisions. The MATLAB toolbox was used for ANN modeling in this paper. The parameters used for the network are tabulated in Table 1.

Table 1. Training parameters for the network.

\begin{tabular}{ll}
\hline Number of neurons on the layer & Input: 1 hidden: 2 output: 1 \\
Initial weights and biases & Randomly between -1 and 1 \\
Activation function & Tansig \\
Learning rate & 0.05 \\
Momentum constant & 0.95 \\
Epochs & 1000 \\
\hline
\end{tabular}

Several independent runs with different initial random weights were performed to achieve the best possible solution. The MSE during the learning process of the network was evaluated by

$$
M S E=\frac{\sum_{N}^{i=1}\left(T_{i}-O_{i}\right)^{2}}{N}
$$

where $T$ and $O$ are target and output values, respectively. The weights are again adjusted between the hidden and output layer and are calculated by Eq.(10)

$$
\Delta w_{j i}(n)-\alpha \Delta w_{j i}(n-1)+\eta \delta_{j}(n) y_{i}(n)
$$

where $\Delta w_{j i}(n)$ is the change in weights, $\alpha$ is the momentum coefficient $\delta_{j}(n)$ is the error, $\eta$ is the learning rate and $y_{i}(n)$ is the output. The results were tested with the experimental data that were not presented during the training process after successful training. The results were again compared with using $\mathrm{R}^{2}$ and MSE. $\mathrm{R}^{2}$ is defined as the proportion of the variance in the dependent variable that is predicted from the independent variable and is given by

$$
R^{2}=1-\left(\frac{\sum_{i=1}^{N}\left(T_{i}-O_{i}\right)^{2}}{\sum_{i=1}^{N}\left(O_{i}\right)^{2}}\right)
$$

\section{Experimental setup and case study}

The experiments conducted by Parida et al. [30] on Monel-400 to measure the surface roughness and flank wear were used for the present work. The tests were performed on an HMT center lathe with $1200 \mathrm{rpm}$ maximum speed and $6 \mathrm{~kW}$ spindle power. A round bar of Monel-400 workpiece of diameter $40 \mathrm{~mm}$ and $300 \mathrm{~mm}$ length was used in the experiments. A TiN coated inserts were utilized for machining operation which was fitted to PSBNR 2525 M12 tool holder. To avoid error in the measurements, 
each experimental run was carried out three times and a new cutting edge of the tool was used for each run. The flank wear of the cutting tool and roughness of machined surface were measured using an optical microscope and Taylor Hobson Surtronic S-100 Series surface roughness tester, with cut off value $0.8 \mathrm{~mm}$.

\section{Results and discussion}

Power law and ANN model have been used for modeling surface roughness and flank wear during hot turning of Monel-400. The model parameters of the power-law equation were determined from experimental data. Also, the same data set was used for training and validation of the ANN model to carry out the comparison between the results of the two models (power law and ANN model). The Eq. (12) and (13) represent the model of the surface roughness and flank wear respectively.

$$
\begin{aligned}
& R_{a}=5.6840 V^{-0.1792} F^{0.0568} D^{0.0139} T^{0.0029} \\
& F W=0.1633 V^{0.1428} F^{0.0729} D^{0.0503} T^{-0.0007}
\end{aligned}
$$

where $R_{a}$ and $F w$ are surface roughness and flank wear, respectively.

From Eq. (12)

$$
\left(\frac{\partial R_{a}}{\partial V}\right)_{F, D, T}<0,\left(\frac{\partial R_{a}}{\partial F}\right)_{V, D, T}>0,\left(\frac{\partial R_{a}}{\partial D}\right)_{V, F, T}>0, \text { and }\left(\frac{\partial R_{a}}{\partial T}\right)_{V, F, D}>0
$$

This implies that the surface roughness increases with feed rate, depth of cut and temperature but decreases with the increase in cutting speed.

Similarly, from Eq. (13)

$$
\left(\frac{\partial F w}{\partial V}\right)_{F, D, T}>0,\left(\frac{\partial F w}{\partial F}\right)_{V, D, T}>0,\left(\frac{\partial F w}{\partial D}\right)_{V, F, T}>0, \text { and }\left(\frac{\partial F w}{\partial T}\right)_{V, F, D}<0
$$

Which implies that theflank wear increases with the increase in cutting speed, feed rate and depth of cut but decreases with an increase in temperature.

The temperature and cutting speed were found to be the most influential parameters that affect flank wear and surface roughness respectively.

The ANN was trained for 20 values of input and validated for 5 out of 30 experimental input data for both surface roughness and flank wear. The correlation of parameters of surface roughness and flank wear of the ANN model is given in Fig. 3. 

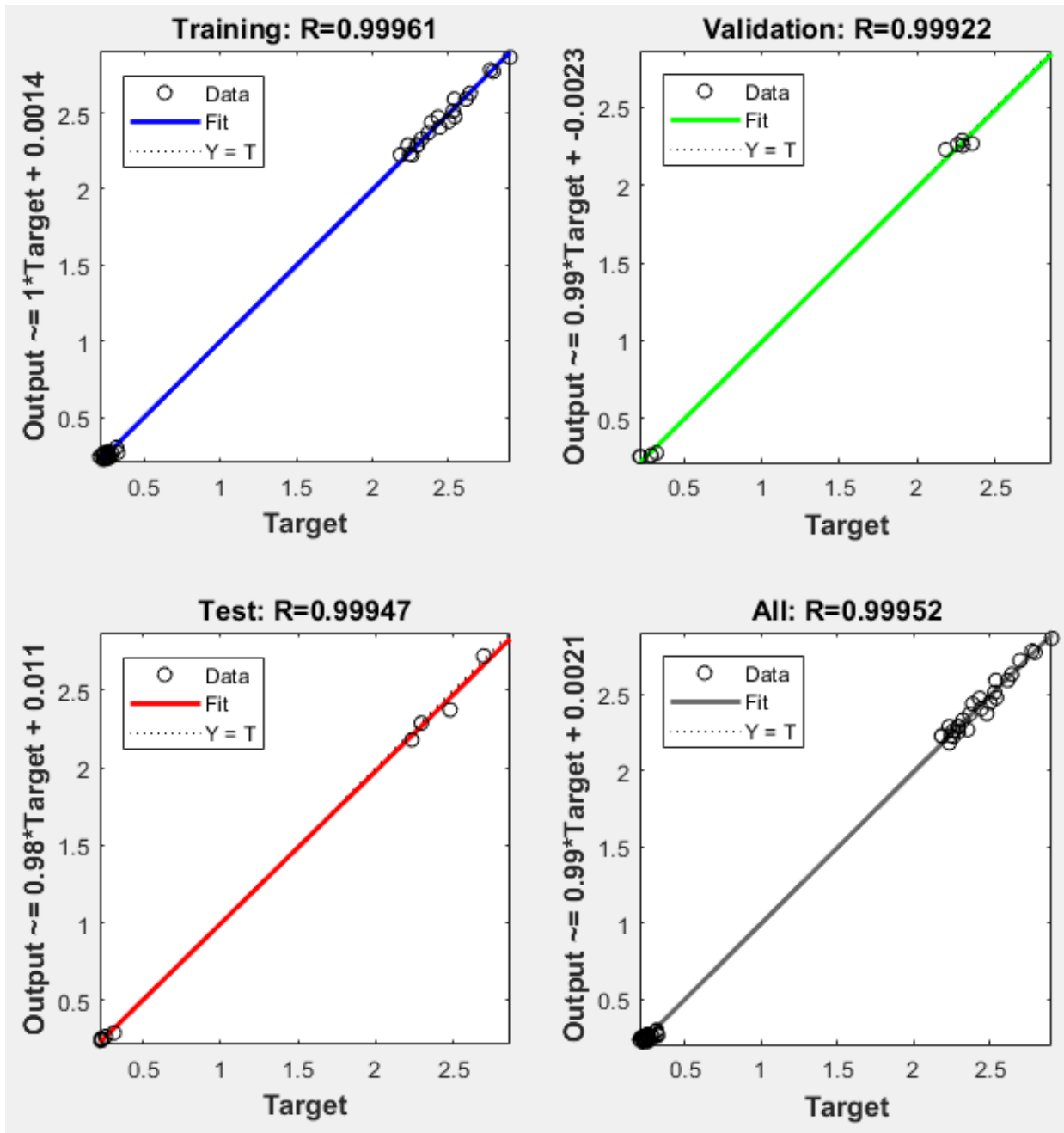

Fig. 3. Correlation of parameters for surface roughness and flank wear.

Further, the comparison of surface roughness and flank wear with the experimental results obtained from the power law and ANN are shown in Fig. 4 and Fig. 5 and Table 2. It can be seen from Fig. 4 and Fig. 5 that the maximum error for surface roughness is about $8.5 \%$ and $4 \%$ for power law and ANN model, respectively. Similarly, the maximum error for flank wear is about $20 \%$ and $17 \%$ power law and ANN model, respectively. 

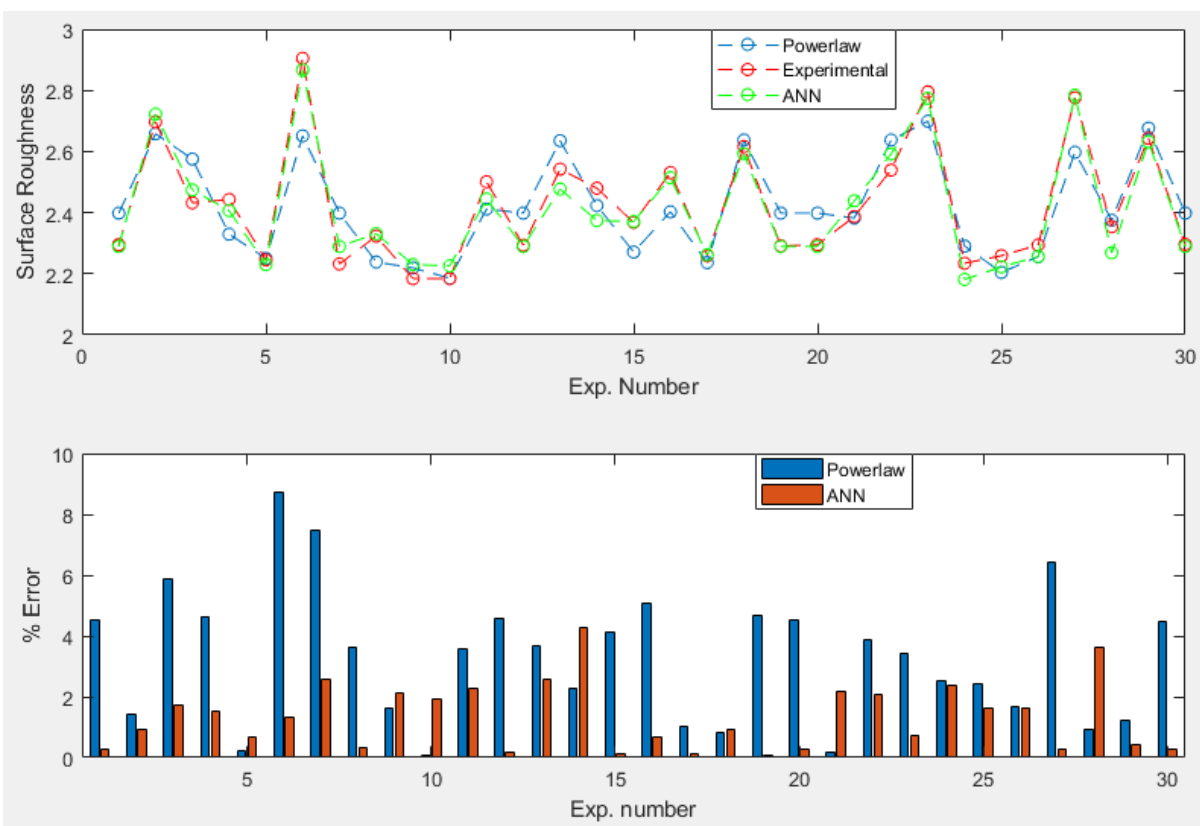

Fig. 4. Comparison of proposed power law and ANN model with experimental results for surface roughness.
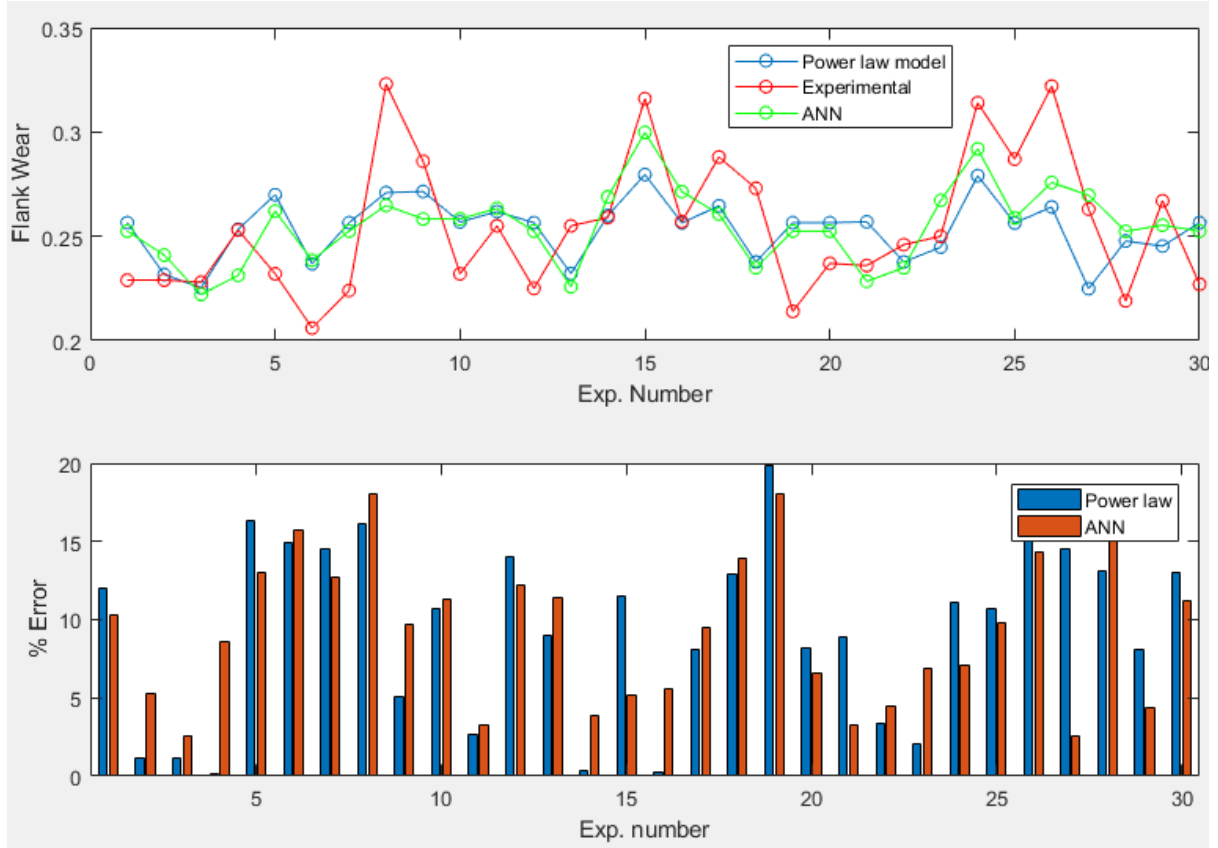

Fig. 5. Comparison of proposed power law and ANN model with experimental results for Flank wear. 
Table 2. Statistical parameters of a proposed power law, ANN, and regression [30] model.

\begin{tabular}{|c|c|c|c|c|c|c|}
\hline & \multicolumn{3}{|c|}{ Surface roughness } & \multicolumn{3}{|c|}{ Flank wear } \\
\hline & $\begin{array}{l}\text { Power } \\
\text { law }\end{array}$ & ANN & [30] & $\begin{array}{l}\text { Power } \\
\text { law }\end{array}$ & ANN & [30] \\
\hline $\mathrm{R}^{2}$ & $99.83 \%$ & $99.91 \%$ & $86.17 \%$ & 98.72 & 98.74 & $94.72 \%$ \\
\hline MSE & 0.0099 & 0.0054 & 0.0105 & 0.00081 & 0.00082 & 0.0025 \\
\hline MAPE & 0.0332 & 0.0596 & 0.0377 & 0.094 & 0.0596 & 0.1151 \\
\hline
\end{tabular}

\section{Optimization of machining parameters}

Multi-objective optimization, using the Genetic Algorithm (GA) is an efficient method for solving nonlinear and constrained problems. GA originated from the principle of natural genetics and been widely used for engineering problems, Zain et al. [31]. GA creates the Pareto Front with multiple outputs for optimal selection of parameters. The output of GA depends on the size of the population, selection type, GA operators i.e. mutation, and crossing over. In the present work, tournament selection was used to select individuals from the given population at random. Crossover involves a combination of two individuals to form parents or offspring for the next generation. While mutation causes random changes in the individual to widen search space for attaining genetic diversity. Adaptive feasible type function is used to select the search direction based on the last successful generation. Aim of multi-objective optimization in this work is to establish various optimum conditions for the chosen surface roughness and flank wear. The Eqs. (13) and (14) developed in the previous section by the power-law model are taken as the objective functions for optimization. Since, GA is based on maximum survival of best individuals, the objective functions for minimization of surface roughness, $R_{a}$ and $F w$ has been taken directly. The objective functions Eq. (12) and (13) are subjected to the following boundary conditions:

$40 \leq$ Cutting speed $(V) \leq 100$

$0.1 \leq$ Feed rate $(F) \leq 0.15$

$0.5 \leq$ Depth of cut $(D) \leq 1$

$30 \leq$ Temperature $(T) \leq 600$

The MATLAB toolbox was used for optimizing the objective functions. The Pareto front is shown in Fig. 6 and presented in Table 3. It consists of a set of possible solutions. Based on the priority given for each response variable, the particular combination is selected. In present work, equal priority is given to $R a$ and $F w$. The corresponding operating parameters are chosen as the optimum parameters. An optimum value of $R a$ and $F w$ were found to be 2.1973 and 0.2565 , respectively. The corresponding parameters $V=99.2758 \mathrm{~mm} / \mathrm{min}, \quad F=0.1014 \mathrm{~mm} / \mathrm{rev}$, $D=0.5003 \mathrm{~mm}$, and $T=92.9177^{\circ} \mathrm{C}$. 
Table 3. Pareto front of GA.

Input parameters

Responses

\begin{tabular}{lllllll}
\multicolumn{2}{l}{$\begin{array}{l}\text { Cutting } \\
(\mathrm{V})\end{array}$} & $\begin{array}{r}\text { speed Feed } \\
(\mathrm{F})\end{array}$ & $\begin{array}{l}\text { rate Depth of cut Temperature } \\
(\mathrm{D})\end{array}$ & & $\begin{array}{l}\text { Surface } \\
\text { roughness }(\mathrm{Ta})\end{array}$ & $\begin{array}{l}\text { Flank wear } \\
(\mathrm{Fw})\end{array}$ \\
\hline 99.2758 & 0.1014 & 0.5003 & 92.9177 & & 2.1973 & 0.2565 \\
40.2071 & 0.1001 & 0.5004 & 130.5807 & & 2.5842 & 0.2252 \\
40.2071 & 0.1001 & 0.5004 & 130.5807 & & 2.5842 & 0.2252 \\
51.7393 & 0.1005 & 0.5006 & 112.2836 & & 2.4696 & 0.2336 \\
64.1634 & 0.1022 & 0.5038 & 110.8685 & & 2.3786 & 0.2412 \\
85.0816 & 0.1028 & 0.5019 & 104.0428 & & 2.2616 & 0.2512 \\
99.2758 & 0.1014 & 0.5003 & 92.9177 & & 2.1973 & 0.2565 \\
87.8363 & 0.1010 & 0.5009 & 98.1233 & & 2.2460 & 0.2520 \\
50.0571 & 0.1013 & 0.5010 & 116.5851 & 2.4856 & 0.2326 \\
73.6425 & 0.1001 & 0.5003 & 112.6392 & 2.3177 & 0.2456 \\
60.3162 & 0.1008 & 0.5010 & 117.0805 & 2.4033 & 0.2388 \\
91.5014 & 0.1011 & 0.5006 & 94.5690 & 2.2294 & 0.2535 \\
82.0776 & 0.1015 & 0.5005 & 97.5883 & 2.2739 & 0.2497 \\
71.0472 & 0.1024 & 0.5022 & 127.7981 & 2.3366 & 0.2447 \\
41.5800 & 0.1001 & 0.5011 & 128.7734 & 2.5688 & 0.2263 \\
61.2484 & 0.1034 & 0.5015 & 112.6683 & 2.4000 & 0.2398 \\
57.5948 & 0.1071 & 0.5039 & 107.4933 & 2.4313 & 0.2384 \\
68.8369 & 0.1013 & 0.5019 & 105.5925 & 2.3471 & 0.2435 \\
\hline
\end{tabular}

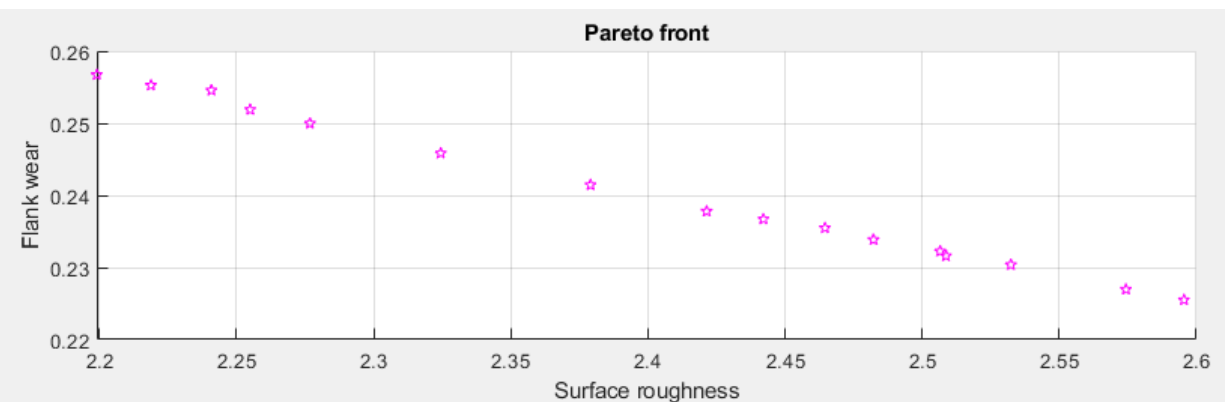

Distance of individuals

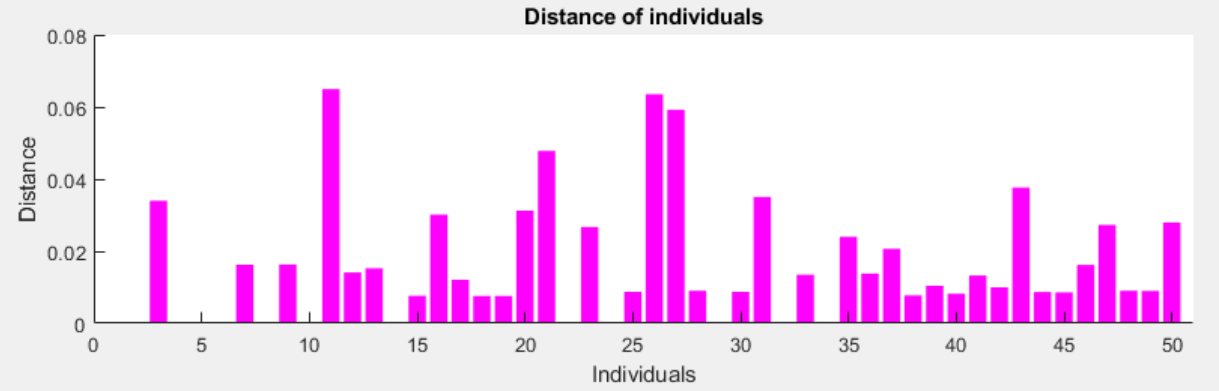

Fig. 6. Pareto Front of optimization. 


\section{Conclusion}

The models for surface roughness and flank wear, during the hot turning of Monel400 , are obtained using power law and ANN in this paper. The influences of machining parameters on surface roughness and flank wear have been analyzed based on proposed models. The optimal values of the machining parameters were determined by multiobjective optimization using a genetic algorithm. The power-law model developed was used as an objective function. The following conclusions were drawn from this work:

The $R^{2}, M S E$ and MAPE of the power-law model were found to be $99.83 \%$, $9.9 \times 10^{-4}$ and $3.32 \times 10^{-2}$, and that of ANN model were found to be $99.91 \%$, $5.4 \times 10^{-4}$ and $5.96 \times 10^{-2}$, respectively. It was concluded from the above statistical parameters that the proposed models are competent to predict the surface roughness and flank wear.

The surface roughness decreased with the increase of cutting speed and feed rate, whereas an increase in temperature and depth of cut caused an increase of the surface roughness.

An increase in cutting speed, feed rate and depth of cut, lead to an increase of flank wear. However, an increase in temperature up to a specific limit there decreased the tool wear and after that, the flank wear increased with the increase of temperature.

The temperature was the most influential factor which affects flank wear, whereas cutting speed was the most affecting factor influencing the surface roughness.

Using a genetic algorithm the optimal values of the machining parameters-cutting speed, feed rate, depth of cut and temperature were found to be $99.2758 \mathrm{~mm} / \mathrm{min}, 0.1014$ $\mathrm{mm} / \mathrm{rev}, 0.5003 \mathrm{~mm}$ and $92.9177^{\circ} \mathrm{C}$, respectively. The corresponding values of surface roughness $(R a)$ and flank wear $(F w)$ were found to be $2.1973 \mu \mathrm{m}$ and $0.2565 \mathrm{~mm}$, respectively.

\section{References}

[1] A. Srithar, K. Palanikumar, B. Durgaprasad: Procedia Engineering, 97 (2014) 72 -77 .

[2] K. Katuku, A. Koursaris and I. Sigalas: J Mater Process Technol, 209 (2009) 2412-2420.

[3] S. Yamamoto, H. Nakajima, H. Miyaji: Trans Iron Steel Inst Jpn, 81 (7), 2005, 721-726.

[4] T. Özel, Y. Karpat: International Journal of Machine Tools Manufacture, 45 (2005) 467-479.

[5] Z. Hessainia, A. Belbah, M.A. Yallese, T. Mabrouki, J.F. Rigal: Measurement, 46 (2013) 1671-1681.

[6] N. Mandal, B. Doloi, B. Mondal, R. Das: Measurement, 44 (2011) 2149-2155.

[7] E.O. Ezugwu: J Brazilian Soc Mech Sci Eng, 26 (2004) 1-11.

[8] E.O. Ezugwu, Z.M. Wang, A.R. Machado: J Mater Process Technol, 86 (1999) 116.

[9] A.K. Parida, K.P. Maity: Adv Eng Forum, 16 (2016) 24-32.

[10] L. Özler, A. Inan, C. Özel: Int J Mach Tools Manuf, 41 (2001) 163-172.

[11] T.L. Ginta, A.K.M.N. Amin, M.A. Lajis, A.N.M. Karim, H.C.D.M. Radzi: Eur J Sci Res, 27 (2009) 384-391.

[12] T.L. Ginta, A.K.M.N. Amin, A.N.M. Karim, A.U. Patwari, Modeling and optimization of tool life and surface roughness for end milling titanium alloy $\mathrm{Ti}-$ $6 \mathrm{Al}-4 \mathrm{~V}$ using uncoated WC-Co inserts, CUTSE Int. Conf. (2008) 24-27. 
[13] S. Ranganathan, T. Senthilvelan: Int J Adv Manuf Technol, 56 (2011) 455-462.

[14] A.K. Parida, K.P. Maity: Int J Eng Res Africa, 24 (2016) 64-70.

[15] A.K. Parida, K.P. Maity: Int J Eng Res Africa, 24 (2016) 57-63.

[16] A.K. Parida, K.P. Maity: Adv Eng Forum, 16 (2016) 16-23.

[17] G. Zhang, Z. Zhang, W. Ming, J. Guo, Y. Huang, X. Shao: Int J Adv Manuf Technol, 70 (2014) 2097-2109.

[18] H. Aouici, H. Bouchelaghem, M.A. Yallese, M. Elbah, B. Fnides: Int J Adv Manuf Technol, 73 (2014) 1775-1788.

[19] A.K. Gupta: Int J Prod Res, 48 (2010) 763-778.

[20] H. Aouici, M.A. Yallese, K. Chaoui, T. Mabrouki, J. F. Rigal: Meas J Int Meas Confed, 45 (2012) 344-353.

[21] R.D. Koyee, U. Heisel, R. Eisseler, S. Schmauder: J Manuf Process, 16 (2014) 451-467.

[22] A.K. Parida: Iran J Sci Technol Trans Mech Eng, 43 (2018) 155-164.

[23] G. Venkatesh, D. Chandrakar: Silicon, 9 (2017) 867-877.

[24] S. Palani, U. Natarajan, M. Chellamalai: Mach Vis Appl, 24 (2013) 19-32.

[25] M. Durairaj, S. Gowri: Procedia Eng, 64 (2013) 878-887.

[26] R. Venkata Rao, V.D. Kalyankar: Scientia Iranica, 20 (2013) 967-974.

[27] I. Asiltürk, S. Neseli, M.A. Ince: Measurement, 78 (2016) 120-128.

[28] S. Selvakumar, R. Ravikumar: Indian J Eng Mater Sci, 21 (2014) 397-408.

[29] M. Hanief, M. F. Wani: Applied Surface Science, 357 (2015) 1573-1577.

[30] A. K. Parida, K. Maity: Measurement, 137 (2019) 375-381.

[31] A.M. Zain, H. Haron, S. Sharif: Expert Syst Appl, 37 (2010) 4650-4659.

\section{(c) (i) Creative Commons License}

This work is licensed under a Creative Commons Attribution 4.0 International License. 